BULLETIN Bulletin hispanique

HISPANIQUE Université Michel de Montaigne Bordeaux

119-1 | 2017

Autorité et pouvoir dans le théâtre du Siècle d'Or

\title{
Antología Cátedra de Poesía de las Letras Hispánicas
}

Cátedra, Madrid, 2016

Luis Pablo Núñez

\section{OpenEdition}

Journals

Edición electrónica

URL: http://journals.openedition.org/bulletinhispanique/5009

DOI: $10.4000 /$ bulletinhispanique.5009

ISBN: 979-10-300-0142-6

ISSN: 1775-3821

Editor

Presses universitaires de Bordeaux

Edición impresa

Fecha de publicación: 15 junio 2017

Paginación: 398-401

ISBN: 979-10-300-0141-9

ISSN: 0007-4640

Referencia electrónica

Luis Pablo Núñez, «Antología Cátedra de Poesía de las Letras Hispánicas », Bulletin hispanique [En línea] 119-1 | 2017, Publicado el 15 junio 2017, consultado el 24 septiembre 2020. URL : http:// journals.openedition.org/bulletinhispanique/5009; DOI : https://doi.org/10.4000/bulletinhispanique. 5009

Este documento fue generado automáticamente el 24 septiembre 2020

Tous droits réservés 


\section{Antología Cátedra de Poesía de las Letras Hispánicas}

Cátedra, Madrid, 2016

Luis Pablo Núñez

\section{REFERENCIA}

Antología Cátedra de Poesía de las Letras Hispánicas. Selección e introducción de José Francisco Ruiz Casanova. 12. ed. corregida y aumentada, Madrid, Cátedra, 2016. 1344 pp. (Letras Hispánicas 500). ISBN 978-84-376-3596-5

1 «La historia de la poesía no podría concebirse sin la presencia constante de las antologías», señala Francisco Ruiz Casanova en la introducción a esta Antología Cátedra de Poesía de las Letras Hispánicas. Y así es, pues, frente a otros géneros, la poesía ha sido publicada frecuentemente formando agrupaciones de textos, ya sean de un solo autor o de varios, de una o de varias épocas históricas, llamándolas unas veces cancioneros $y$, otras, romanceros o florilegios, poesía escogida o antologías. El hecho de ser composiciones normalmente breves y aislables por su sentido completo ha provocado que hayan sido desgajadas de sus poemarios originarios, aunque, como otras obras literarias, estos puedan contar con una estructura o unidad temática.

2 La cuestión es que esta forma basada necesariamente en la selección ha acabado configurando un canon de autores y obras representativos de nuestra literatura, y a este punto y a la razón de ser de las antologías, a su germen y desarrollo histórico, dedica Francisco Ruiz la larga introducción, de más de cien páginas, más un apéndice bibliográfico con las principales antologías de poesía española publicadas desde el siglo XV hasta 2016, señalando cinco de ese año.

3 Y ya que tratamos precisamente de historia de las antologías, no está de más trazar la de esta que nos ocupa. La antología Cátedra de poesía se publicó por primera vez en 1998 con motivo del vigesimoquinto aniversario de la colección «Letras Hispánicas» (LH), creada en 1973. Para conmemorarlo, la editorial Cátedra pidió al profesor José 
Francisco Ruiz Casanova de la Universidad Pompeu Fabra que realizara una selección de poemas de los casi doscientos autores publicados hasta ese momento en la colección. Fueron seleccionados 628 poemas, pero, con el paso de los años y la aparición de nuevos volúmenes en la colección, la antología se ha ido actualizando, hasta llegar a la quinta edición ampliada (12..$^{\mathrm{a}}$ si se incluyen las reimpresiones), con 990 poemas de 265 autores: esta se publicó a finales de 2016 y es sobre la que tratamos.

La meritoria labor de la editorial Cátedra y de la colección «Letras Hispánicas» es innegable. Sus característicos volúmenes negros de formato bolsillo, con los que han estudiado ya varias generaciones, están presentes en las bibliotecas escolares y universitarias de la Península e Hispanoamérica, así como en otras muchas extranjeras (junto con los también reconocidos de "Clásicos Castalia» y "Clásicos Castellanos» de Espasa Calpe). Los que en principio iban a ser ediciones para el uso de estudiantes de bachillerato y primeros cursos de universidad, han acabado convirtiéndose en obras de referencia por la calidad de sus ediciones, anotaciones y estudios introductorios realizados por los hispanistas más reconocidos de su ámbito. Pensemos, por ejemplo, en la cuidada edición del Libro de buen amor del Arcipreste de Hita realizada por Alberto Blecua o en la magistral introducción de Domingo Ynduráin a la poesía de san Juan de la Cruz.

5 Asimismo Cátedra ha recuperado textos marginales de nuestra historia literaria bajo ediciones rigurosas que de otra manera habrían permanecido olvidados: con ello ha ayudado a entender de manera más amplia el panorama de la literatura en español. La gran cantidad de títulos publicados, casi ochocientos, ha conformado, como dice la propia editorial en la portada de su catálogo, « un recorrido por la literatura en lengua española desde la Edad Media hasta nuestros días ».

6 La Antología Cátedra de Poesía de las Letras Hispánicas presenta, pues, un panorama cronológico y representativo de mil años de poesía en lengua castellana, con autores españoles e hispanoamericanos como Jorge Manrique, Garcilaso, Sor Juana, Quevedo, Lope de Vega, José Martí, Lezama Lima, Octavio Paz o Gamoneda, entre tantos otros. En ella se puede recorrer en ocasiones la trayectoria de un autor a través de sus diferentes poemarios, como Juan Ramón Jiménez o Cernuda, pero su propósito fundamental es el de dar a conocer al lector otros poetas, quizá no descubiertos hasta ahora, y animar a leerlos.

7 Lógicamente en la editorial Cátedra no han aparecido todas las obras de todos los poetas de la lengua española, con lo que, como esta selección parte de lo que está en ella publicado, puede resultar en algunos casos incompleta: es lo que ocurre, por ejemplo, con José Hierro, del que únicamente se seleccionan algunos poemas de su Libro de las alucinaciones (1964) y Guardados en la sombra (2002), pero no de otros (como Quinta del 42, Cuaderno de Nueva York, etc.) porque han sido publicados por otras editoriales, no en Cátedra. De un modo similar sucede con Luis García Montero: en esta antología Cátedra se seleccionan poemas del volumen editado por José Luis Morante (LH 684: Ropa de calle: Antología poética 1980-2008), lo que deja sin incluir los libros más recientes del autor publicados en Visor tras Vista cansada (2008): Un invierno propio (2011) y Balada en la muerte de la poesía (2016). Puede incluso acontecer que no se incluyan autores por el hecho de no haberse publicado aún ningún título en la colección: es lo que sucede con Gonzalo Rojas, María Victoria Atencia o Dionisia García, por ejemplo. Estas carencias, no obstante, se deben a cuestiones editoriales y son reconocidas por el editor cuando habla, necesariamente, de las limitaciones del antólogo. 
Otra carencia, quizá atribuible al seleccionador, sea la de no incluir textos en lenguas gallega, catalana o vasca -lo que parece ir en contra del título de «letras hispánicas»- ni de autores bilingües, a pesar de que para la Edad Media sí se incluyen cantigas, y así no encontramos ni textos gallegos de Rosalía de Castro, ni poemas en catalán de Pere Gimferrer (sí incluido en la antología con poemas de Arde el mar, ¿LH 383, 1994, y LH 641, 1999, ambos?) ni tampoco de Joan Margarit (el cual sí cuenta con un volumen en la colección publicado en 2006, LH 589, Arquitecturas de la memoria, con poemas traducidos al castellano por el propio autor). Del mismo modo ocurre con los poemas de Gabriel Aresti, cuyo volumen bilingüe Maldan Behera [= Pendiente abajo]; Harri eta Herri [= Piedra y pueblo] (LH 111, 1984) en edición de Javier Atienza se publicó en Cátedra, pero parece haberse descatalogado desde hace lustros...

9 En cuanto a la construcción de la antología, algunos textos proceden no ya de ediciones de la poesía de un autor, sino de antologías previas publicadas en la propia colección LH: en este caso, la antología es una selección de otra de la que se nutre. Es el caso de los textos tomados de Joven poesía española (LH 107, 1982), de donde se extraen poemas del mencionado Gimferrer, Antonio Colinas o José Luis Jover; o de la de Juan Cano Ballesta, Poesía española reciente (1980-2000) (LH 510, 2001), de donde se extraen los de Ana Rossetti, Juan Manuel Bonet, Justo Navarro, Ada Salas o Juan Carlos Suñén. El propio Ruiz Casanova cita en la p. 73 las dieciséis antologías que ha manejado para componer la suya. En todo caso, esta procedencia es lo que explica que en estos autores normalmente solo haya un poema seleccionado.

10 En cuanto a la ordenación de los materiales, además de la división por épocas y siglos establecida en la historia literaria (Edad Media, Siglos de Oro, siglo XVIII, siglo XIX, siglo XX), se ordenan los autores por la fecha de su nacimiento. La más joven es Ada Salas, nacida en 1965, con la que finaliza la antología, por lo que en esta selección no encontraremos poesía de autores menores de 50 años (para la poesía más reciente, habrá que recurrir a otras editoriales). Tras el nombre de cada autor o autora se insertan entre corchetes los números de los volúmenes de la colección Letras Hispánicas (LH) de donde han sido seleccionados los poemas, y se añaden al final de la antología unos índices alfabéticos de primeros versos, de autores y obras anónimas y un índice numérico de los títulos de poesía de la colección Letras Hispánicas.

11 Es preciso realizar una última consideración en este análisis crítico que estamos realizando de la antología Cátedra, y es la que se refiere a la ortografía. Editar muestras de obras aparecidas a lo largo de varios siglos conlleva dificultades, pues la lengua ha evolucionado y los sistemas ortográficos también. El antólogo se encuentra con una dificultad grande, pues por un lado está el respeto al texto original y por otro favorecer la legibilidad y comprensión de los poemas por parte del lector actual. Sabiamente, Ruiz Casanova ha respetado aquí "al máximo el texto aparecido en las ediciones correspondientes, y únicamente he subsanado aquellas erratas que se resisten a desaparecer del libro aun cuando se corrigiera mil veces» (p. 74). Teniendo en cuenta que cada edición del texto fue realizada por un especialista, habría sido complejo y trabajoso modificar o unificar esos textos. Del mismo modo, incluir anotaciones sobre variantes textuales, modernización ortográfica, etc., habría supuesto crear un volumen inmanejable y ajeno a la voluntad divulgativa de esta edición.

12 Sirva lo dicho para avisar únicamente al lector de que en esta antología podremos encontrar textos con ortografía de época o modernizada, de acuerdo con los criterios que haya seguido el editor en cada título. Así, la poesía de Garcilaso de la Vega se ha 
modernizado, pero pocas páginas antes podremos leer la de Boscán con ortografía de época: «fantasías bivas», "s'asienta», "porque'sta ley se conservase», «congoxarme» (pp. 258-259, y del mismo modo en san Juan de la Cruz: «entre las açucenas olvidado» (p.341), etc. En el caso de la literatura medieval, a esto se suma la carencia de notas explicativas, que han sido suprimidas por cuestiones de espacio, lo que hace en ocasiones difícil la comprensión ante aspectos históricos o culturales. Señalo también una errata notada para que se elimine en la siguiente edición: Luis Rosales, p. 997, «y llevarle el embozo hasta la cara / como una papeleta de desahucio».

13 En conclusión, es muy bienvenida esta nueva edición aumentada de la Antología Cátedra de Poesía de las Letras Hispánicas. Tener reunida en una sola obra una muestra tan amplia y completa de la poesía escrita en español, desde las anónimas cancioncillas populares medievales y los grandes autores del Siglo de Oro hasta los poetas actuales, en un libro de 1150 páginas -1340 si se suma la amplia introducción y los índices del final-, es una invitación para el descubrimiento de nuevos autores y la profundización en otros ya conocidos.

14 Las muchas ediciones que se han publicando de la obra desde su primera edición dan muestra del interés hacia esta antología, que ha superado ampliamente su circuito escolar. El hecho de que sea asimismo asequible por su precio aumentará sin duda su difusión. Felicitamos a la editorial por su iniciativa de divulgación de la poesía y por seguir incorporando nuevos autores y obras en su colección.

\section{AUTORES}

\section{LUIS PABLO NÚÑEZ}

Universidad de Granada 